\title{
Improving sustainability in wood coating: testing lignin and cellulose nanocrystals as additives to commercial acrylic wood coatings for bio- building
}

\author{
Jasmina Jusic ${ }^{(1)}$, \\ Swati Tamantini ${ }^{(1)}$, \\ Manuela Romagnoli ${ }^{(1)}$, \\ Vittorio Vinciguerra ${ }^{(1)}$, \\ Elena Di Mattia ${ }^{(2)}$, \\ Florian Zikeli ${ }^{(1-3)}$, \\ Massimo Cavalera ${ }^{(4)}$, \\ Giuseppe Scarascia Mugnozza ${ }^{(1)}$
}

$\square$ (1) Department of Innovation in Biological, Agro-Food and Forest Systems - DIBAF, University of Tuscia, Viterbo (Italy); (2) Department of Agricultural and Forest Sciences - DAFNE, University of Tuscia, Viterbo (Italy); (3) Institute of Chemical, Environmental and Bioscience Engineering, Technische Universität, Wien (Austria); (4) FINEDIN s.r.l., Taviano, LE (Italy)

@ Manuela Romagnoli (mroma@unitus.it)

Received: Feb 13, 2021 - Accepted: Sep 02, 2021

Citation: Jusic J, Tamantini S, Romagnoli M, Vinciguerra V, Di Mattia E, Zikeli F, Cavalera M, Scarascia Mugnozza G (2021). Improving sustainability in wood coating: testing lignin and cellulose nanocrystals as additives to commercial acrylic wood coatings for biobuilding. iForest 14: 499-507. - doi: 10.3832/ ifor3782-014 [online 2021-11-11]

Communicated by: Mauro Maesano
Wood use in bio-building should be considered as one of the main pillars of sustainability. According to international standards, beech wood (Fagus sylvatica $L_{\text {.) }}$ is a rather less durable species as it is subject to degradation due to weathering, though it is abundantly available to a more intense use. Service life of beech products and wood products in general can be enhanced by different methods, such as heat treatments, but new chances are offered by coating technologies. However, to ensure protection from wood-destroying organisms, most commercial coatings include components that could harm human health, other organisms and the environment. Therefore, coating industry has to develop more eco-friendly solutions in order to decrease its impact on human health and environment. The objective of this article was to modify commercial acrylic varnish by adding cellulose nanocrystals (CNC) and lignin (LN) extracted from beech wood and investigate their effect on water sorption, additive dispersion in the coating matrix and coating resistance to bacterial attack. Contact angle, weight gain and colour difference were analysed and FT-IR mapping was applied. The performance of CNC was promising, as it enhanced water sorption of the modified coating. However, protection against bacterial attack was not satisfying. On the other hand, chemically unmodified lignin did not show positive effects as component in the coating formulation. Nevertheless, the currently limited usage of these two renewable and abundant resources urgently calls for their more efficient utilization, in order to create additional value with industry side-streams producing novel bio-based materials. Further experiments are needed in order to obtain better disper sion of the particles and higher resistance to bacterial attacks.

Keywords: Acrylic Waterborne Coating, Beech Wood, Fagus sylvatica, Lignin, Cellulose Nanocrystal (CNC), FT-IR Mapping, Antibacterial Activity

\section{Introduction}

Utilization of wood in bio-building could be considered as one of the main pillars of sustainable construction. Yet, the full exploitation of wood as a construction material still requires some weak points to be solved. Indeed, the risk of degradation caused by weathering and biotic attacks is currently the most limiting factor. Moreover, several mechanical properties of wood are lower compared to synthetic and not-renewable materials. A further important concept towards a more sustainable approach is the use of wood from short supply chains (De Angelis et al. 2018, Romagnoli et al. 2019), but so far it has been mainly applied to biomass production for energy purposes (Delfanti et al. 2014, Paletto et al. 2019). Nevertheless, recent findings on the use of non-durable wood, such as beech and Corsican pine, in biobuilding applications were fairly promising (Brunetti et al. 2020, Sciomenta et al. 2021). According to UNI-EN-350 (2016), beech has less durable wood as it is susceptible to degradation by weathering. The service life of beech products must be addressed especially when used in the most severe conditions (i.e., risk class 4 , according to UNIEN-335 2013). Increasing the durability of beech wood by sustainable methods is still one of the major challenges. To this aim, the successful use of physical methods such as heat treatments (De Angelis et al. 2018, Romagnoli et al. 2015) have been recently reported, but the novel and greener generation of wood coatings offer new interesting opportunities. Coating technology provides surface protection, decorative finishes and numerous special functions for commodities. To ensure protection from wood-destroying organisms, coatings are often composed of synthetic compounds with biocidal functions (Zmihorska-Gotfryd 2004) that were proved to be harmful for human health. Many attempts were carried out to replace fossilbased components of coatings with natu- 
ral compounds (Teaca et al. 2019), but still much work is required for their industrial use in high-technology applications. Currently, a reasonable compromise is the addiction of natural compounds to commercial coatings which can maintain or even increase their performances. Among the biobased additives which could be success fully used in wood industry, lignin and cellulose-based compounds are the most sustainable in terms of circular economy ( $\mathrm{Ma}$ rini et al. 2020, Zikeli et al. 2018, 2019). Several studies demonstrated that lignin, due to its antioxidant properties, increases the natural decay resistance of wood and the performance of coating in outdoor conditions. To this purpose, promising results were obtained using Kraft lignin (Chirkova et al. 2009, Teaca et al. 2019), Organosolv (Dos Santos et al. 2012) and Acidolysis lignin (Teaca et al. 2019). The performance of lignin as coating component largely depends on its source, the method of extraction, and its application to the woody substrate. So far, all the tests have been carried out in the laboratory, showing promising performances (Huang \& Feng 2016, Zikeli et al. 2018, 2019.). Indeed, several properties of lignin, such as low toxicity, biodegradability, low cost and high availability (Ago et al. 2017), make it a very promising candidate as an additive to synthetic or inorganic materials for wood coatings. Other promising compounds for coating industry are cellulose nanocrystals (CNC). Vardanyan et al. (2014) reported that the addition of CNC to wood coatings did not lower their colour stability and increased weathering performance of the varnished wood surface. Furthermore, multifunctional coatings have been recently developed for wood-based composites or CNC-coating of glass fibres for fibre-reinforced composites (Goswami et al. 2019). CNC also represent a promising component for the development of innovative reinforced wood adhesives, due to their high strength and low weight (Marini et al. 2020). Among the commercial coatings, waterborne synthetic acrylic varnishes are one of the most used for both indoor and outdoor applications. They show high transparency and good UV-resistance, but they do not penetrate wood as deep as oils do. Their main advantage is their resistance to yellowing, but photostability needs to be increased to improve their suitability, e.g., for window frames (Van Den Bulcke et al. 2006, Rao et al. 2019, Akbarnezhad et al. 2020).

The main objective of this study is to investigate the effect of $\mathrm{CNC}$ and beech lignin added to commercial acrylic varnish on colour change, wettability and resistance to bacterial attack. Antibacterial activity was investigated considering a product end use as kitchen tops in contact with food or children's toys, where contact with the mouth cannot be excluded. The selected support was beech wood (Fagus sylvatica $\mathrm{L}$.) which is the most promising species for innovative bio-building applications and the most sustainable thanks to its short supply chain, being widely spread all across Europe.

\section{Materials and methods}

\section{Material}

Flat-grained beech wood samples $10 \times 10$ $\times 3 \mathrm{~mm}(\mathrm{~L} \times \mathrm{T} \times \mathrm{R})$ were taken in tangential direction from one board cut, which was dried in an industrial dry kiln. Wood samples were conditioned in the lab at about $65 \%$ relative humidity $(\mathrm{RH})$ and $21^{\circ} \mathrm{C}$ for one year. Just before coating, the wood samples were sanded with 120 grit sandpaper and wiped clean before measuring the contact angle of the coating.

A commercial water-borne acrylic coating provided by the company Finedin S.r.l. (Taviano, LE, Italy) was applied onto samples. This transparent coating is based on poly (methyl acrylate/methyl methacrylate/butyl acrylate), copolymer dispersion; its solid content is $34 \%$, viscosity is $40-50 " \mathrm{~F} / 4$, and gloss at $60^{\circ}$ is $75-85$, while the $\mathrm{pH}$ was 8.5 . The main function is the protection of wood against impacts and scratches in indoor and outdoor conditions. In the commercial formulation some additives (antimold compounds) were present.

Tab. 1 - Formulation of acrylic- and water-based coatings and corresponding abbreviation in the text. (Av): Acrylic varnish; (CNC): Cellulose nanocrystals (LN): lignin (W): Water.

\begin{tabular}{ll}
\hline Code & Formulation \\
\hline Av & Commercial water-based acrylic coating \\
\hline Av-2CNC & Commercial water-based coating plus cellulose nanocrystals (2\%) \\
\hline Av-2LN & Commercial water-based acrylic coating plus lignin powder (2\%) \\
\hline Av-5CNC & Commercial water-based acrylic coating plus cellulose nanocrystals (5\%) \\
\hline Av-5LN & Commercial water-based acrylic coating plus lignin powder (5\%) \\
\hline W-2CNC & Distilled water plus cellulose nanocrystals (5\%) \\
\hline W-2LN & Distilled water plus lignin powder (2\%) \\
\hline W-5CNC & Distilled water plus cellulose nanocrystals (5\%) \\
\hline W-5LN & Distilled water plus lignin powder (5\%) \\
\hline
\end{tabular}

Commercial acrylic coating was modified with CNC (chemically: cellulose hydrogen sulphate sodium salt) that were purchased from CelluForce Inc. (Montreal, QC, Canada). The spray-dried CNC powder has bulk density of $0.7 \mathrm{~g} \mathrm{~m}^{-3}$, moisture content of 4 $6 \%$ and particle size spanning from 1 to 50 $\mu \mathrm{m}$. CNC crystallites (particle diameter: 2.3$4.5 \mathrm{~nm}$, particle length: $44-108 \mathrm{~nm}$ ) have a hydrodynamic diameter of $70 \mathrm{~nm}$ (Marini et al. 2020).

Acrylic coating was also mixed with lignin, which was kindly provided by Fraunhofer Center for Chemical-Biotechnological Processes CBP (Leuna, Germany). The lignin was extracted from residues of beech wood using an Organosolv process with ethanol-water as solvent (Schulze et al. 2019).

\section{Methods}

The different formulations of Acrylic coating (Av) mixed together with CNC and lignin are summarized in Tab. 1. Lignin and CNC were added also to pure water as additional control samples. The experimental plan is summarized in Fig. S1 (Supplementary material).

Samples were dip-coated for 5 minutes with each formulation and then left to open drying at room temperature for one week.

\section{Colour measurement}

Digital images of the samples were taken using an HP Scanjet 4800 scanner, in order to analyze their CIELAB colour space and coordinates using the open-source graphics software GNU Image Manipulation Program (GIMP v. 2.10.12). According to UNIEN-ISO/CIE-11664 (2019), three different spots per sample were selected and twelve samples per coating formulation were analyzed. The coordinates $a^{*}, b^{*}$ and the lightness $L^{*}$ were measured on the tangential plane. The total colour difference $\left(\Delta E^{*}\right)$ represents the difference in colour between virgin wood and the samples coated with commercial acrylic varnish and with the modified formulations, respectively. $\Delta E^{*}$ was calculated according to the following formula (eqn. 1):

$$
\Delta E^{*}=\sqrt{\left(L_{2}^{*}-L_{1}^{*}\right)^{2}+\left(a_{2}^{*}-a_{1}^{*}\right)^{2}+\left(b_{2}^{*}-b_{1}^{*}\right)^{2}}
$$

\section{Weight and thickness}

Weight of the samples was measured using an electronic analytical scale (model JA503, Jing xin, China). Samples were weighted before coating and after the drying period of one week ( $168 \mathrm{~h})$. For determination of coating thickness, the coating layer was measured using a stereomicroscope (model MZ 16A, Leica Microsystems AG, Wetzlar, Germany) at micron level. Twelve samples per formulation were weighted. A representative sample was cut in half and then the thickness of the coating layer was measured on three spots per sample. 


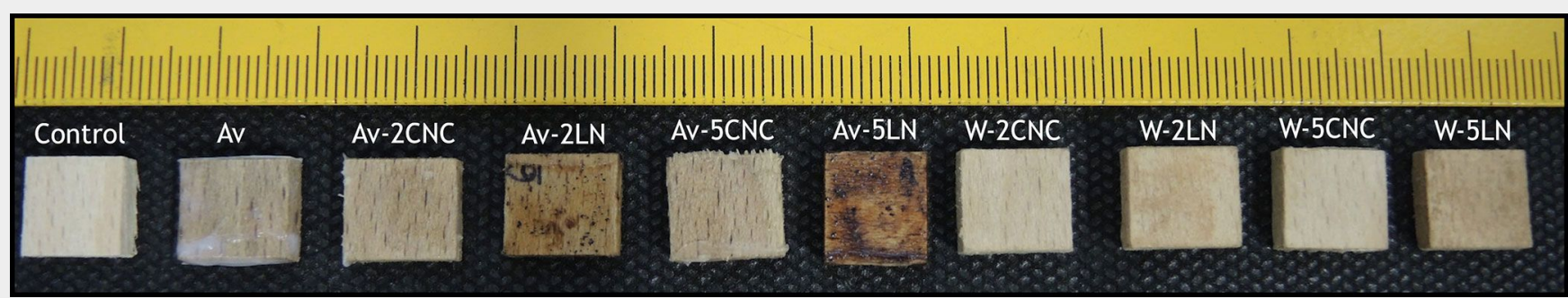

Fig. 1 - Samples treated with different formulations based on acrylic coating (Av) mixed with CNC and LN, as well as control samples treated with water mixed with CNC and LN, respectively. For sample labels, see Tab. 1.

\section{Surface wettability test}

Wetting analysis was executed at room temperature. A small droplet $(4 \mu \mathrm{l})$ of distilled water was taken with a micropipette and dropped on the wood surface (tangential plane). The images were taken immediately after the drop was released and further until complete spreading using a camera (Coolpix ${ }^{\circledR}$ P7700, Nikon, Tokyo, Japan). Time intervals varied among groups. Contact angle was measured on every picture taken on two sides of the drop using GIMP software. Final contact angle was calculated as an average of both sides of the droplets to compensate for sample surface variations. The time needed until complete surface wetting was recorded. One control and one representative sample per coating formulation were chosen for contact angle measurement.

\section{Antibacterial activity test}

The antibacterial test was made using the bacteria-inhibiting ring method (agar plate diffusion test, as described in Gao et al. 2016). Pseudomonas aeruginosa (gram-negative) was used to evaluate the antimicrobial activity. P. aeruginosa is an opportunistic bacterial pathogen with ecological relevance in bioremediation. This species is ubiquitous in nosocomial environment and widely diffused in water and soil. It exhibits also relevant phenotypic traits in biocontrol and in sessile growth (i.e., biofilm formation on material - Sousa et al. 2013). We used an environmental isolate, $P$. aeruginosa strain AP02-1, that is able to degrade crude oil and byproducts was used (Per- fumo et al. 2006).

Two parallel tests were performed. In the first test, a $20 \mu \mathrm{l}$ drop of each coating formulation was spotted on cetrimide agar plates, which were previously inoculated with bacterial suspension $\left(\sim 1.5 \times 10^{5}\right.$ CFU $\mathrm{ml}^{-1}$ diluted in salt solution from ON liquid culture). In the second part of the experiment, one representative wood sample for each formulation was placed on an agar plate with the same amount of bacterial suspension. In this case, the selected groups were the highest percentages of CNC and lignin with both $A v$ and $W$ as matrix. The chosen formulations were compared with virgin wood as control sample. Cetrimide agar (CET $45.5 \mathrm{~g} \mathrm{l}^{-1}$ - Merck, USA) plus $10 \mathrm{ml} \mathrm{l}^{-1}$ of glycerol is the selective growth media for $P$. aeruginosa that was used to avoid the growth of microbial cells accidentally introduced with the coating or the wood samples that were not subjected to prior sterilization. After inoculation, the CET plates were incubated at 37 ${ }^{\circ} \mathrm{C}$.

\section{FTIR spectroscopy and mapping analysis}

Samples of the coating formulations and coated wood samples were analyzed with a FTIR-4100 ${ }^{\oplus}$ Fourier Transform Infrared spectrometer (Jasco Corp., MD, USA) in the range of $2000-1000 \mathrm{~cm}^{-1}$. One representative sample from each group was analyzed in absorbance mode within a surface of $50 \times 50 \mu \mathrm{m}$, using a Jasco IRT-7000 ${ }^{\circledR} \mathrm{Ir}$ tron Infrared microscope. The number of scans was 500.
Statistical analysis

Statistical analyses were carried out with Minitab $^{\circledR}$ Statistical software v. 18.1 (Minitab Inc., State College, PA, USA) to determine the effect of lignin and cellulose addition to the acrylic coating. The differences between the various coating modifications were subjected to principal component analysis (PCA), considering the colour and weight change between virgin wood and treated wood. For the colour variation 3 spots $\times 12$ samples $\times 9$ formulations were analyzed for a total of 324 replicates. Weight data included 1 measurement for each sample $\times 12$ samples $\times 9$ formulations, totalling 108 replicates.

\section{Results}

\section{Colour measurement}

In Fig. 1 the wood samples treated with the different coating formulations are shown.

In Tab. 2 the mean values of the determined CIELAB colour coordinates with the corresponding $\triangle \mathrm{E}^{*}$ values for the samples before and after dip-coating are reported.

From Tab. 2 and Fig. 2, it is evident that beech wood coated with Av showed an increase in the two parameters $a^{*}$ and $b^{*}$, displaying a colour drift towards red-orange, while brightness decreased towards slightly darker tones ( $L^{*}$ shifted from 86 to 79). CNC did not significantly affect brightness, though a certain decrease in $L^{*}$ was observed at both concentrations ( $L^{*}$ before treatment was 82.4 and after dip-coating was 78.4 for $A v-2 C N C$ and for $A v-5 C N C$

Tab. 2 - CIELAB coordinates mean values ( \pm standard deviation) of virgin wood and treated wood before and after dip coating, respectively, and corresponding $\Delta E^{*}$ values.

\begin{tabular}{|c|c|c|c|c|c|c|c|}
\hline \multirow{2}{*}{ Treatment } & \multicolumn{3}{|c|}{ Before dip-coating } & \multicolumn{3}{|c|}{ After dip-coating } & \multirow{2}{*}{$\Delta E^{*}$} \\
\hline & $L^{*}$ & $a^{*}$ & $b^{*}$ & $L^{*}$ & $a^{*}$ & $b^{*}$ & \\
\hline Av & $86.1 \pm 2.6$ & $2.5 \pm 0.6$ & $14.3 \pm 1.2$ & $79.0 \pm 4.4$ & $6.0 \pm 0.8$ & $20.4 \pm 0.9$ & $10.30 \pm 3.48$ \\
\hline$A v-2 C N C$ & $82.4 \pm 5.4$ & $2.7 \pm 0.8$ & $12.0 \pm 1.4$ & $78.4 \pm 5.7$ & $5.3 \pm 1.0$ & $18.3 \pm 0.8$ & $8.76 \pm 2.91$ \\
\hline$A v-2 L N$ & $83.9 \pm 6.7$ & $2.4 \pm 0.9$ & $12.3 \pm 1.0$ & $48.6 \pm 14.0$ & $6.8 \pm 1.8$ & $18.0 \pm 5.1$ & $37.06 \pm 15.24$ \\
\hline$A v-5 C N C$ & $84.1 \pm 6.2$ & $2.5 \pm 0.9$ & $12.5 \pm 1.3$ & $80.5 \pm 7.5$ & $5.3 \pm 1.2$ & $18.3 \pm 0.9$ & $7.93 \pm 2.53$ \\
\hline$A v-5 L N$ & $86.0 \pm 2.8$ & $2.0 \pm 0.5$ & $13.1 \pm 1.1$ & $27.1 \pm 11.0$ & $5.3 \pm 2.5$ & $9.8 \pm 5.0$ & $59.37 \pm 11.38$ \\
\hline W-2CNC & $85.7 \pm 6.3$ & $2.3 \pm 0.9$ & $12.9 \pm 1.6$ & $86.5 \pm 4.6$ & $2.6 \pm 0.8$ & $14.0 \pm 1.2$ & $3.64 \pm 3.62$ \\
\hline W-2LN & $84.5 \pm 4.4$ & $2.2 \pm 0.7$ & $11.7 \pm 0.9$ & $78.5 \pm 7.5$ & $6.0 \pm 1.4$ & $18.3 \pm 1.1$ & $11.05 \pm 5.69$ \\
\hline W-5CNC & $84.5 \pm 5.0$ & $2.2 \pm 0.8$ & $13.1 \pm 0.9$ & $85.9 \pm 4.6$ & $2.1 \pm 0.9$ & $13.8 \pm 0.9$ & $3.04 \pm 1.87$ \\
\hline W-5LN & $87.4 \pm 3.7$ & $2.1 \pm 0.7$ & $13.3 \pm 1.0$ & $69.4 \pm 7.8$ & $8.1 \pm 1.3$ & $20.3 \pm 1.1$ & $20.71 \pm 6.54$ \\
\hline
\end{tabular}


Fig. 2 - Graphs of colour change of beech wood

samples after coating treatment. (a) Biplot of

CIELAB coordinates $a^{*}$ and

$b$ * for Av to Av-2CNC and Av-5CNC; (b) biplot of coordinates $a^{*}$ and $b^{*}$ for Av to Av-2LN and Av-5LN; (c) PCA results for $\triangle E^{*}$; (d) $P C A$ results for weight changes.

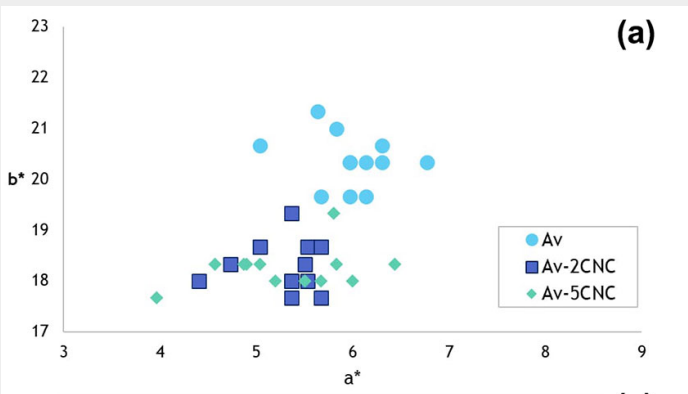

(a)
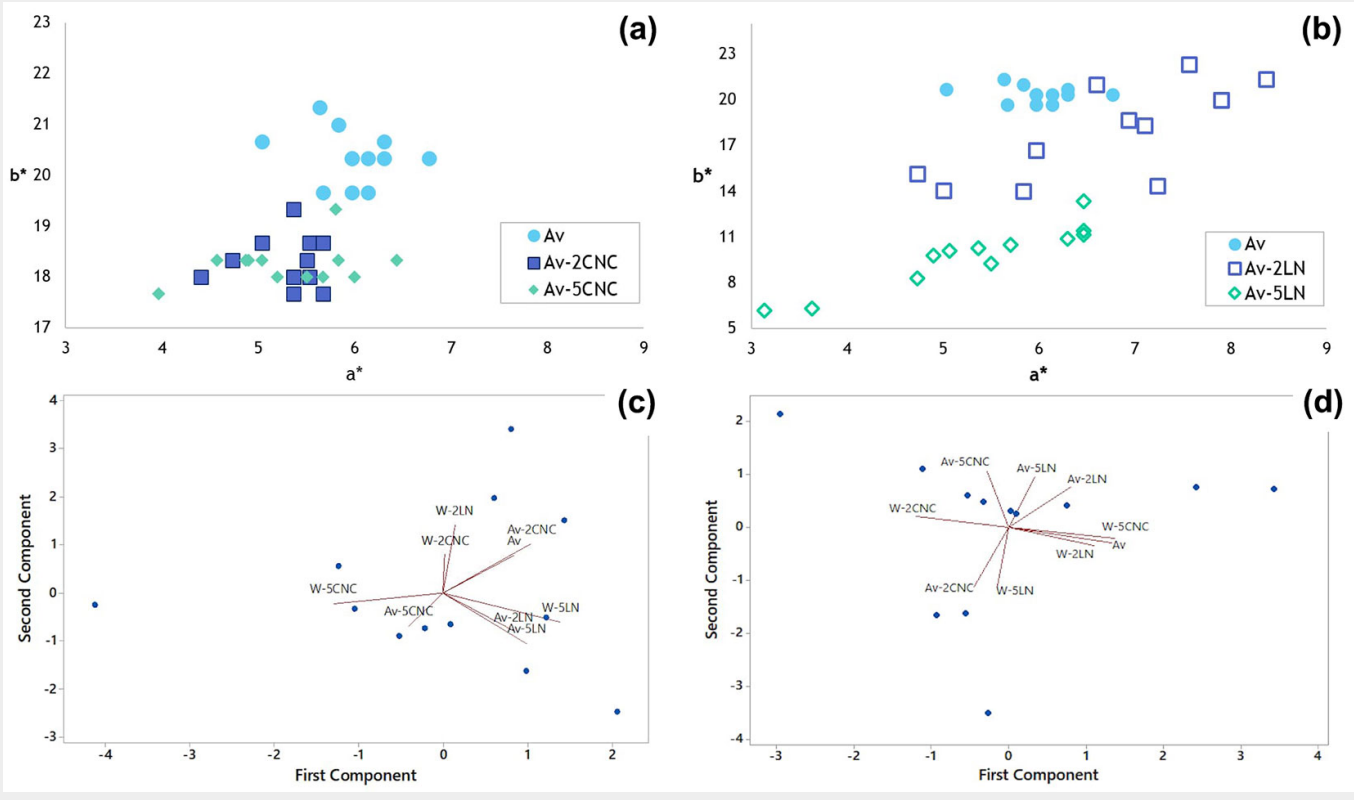

(b)

(d) was 84.1 and then became 80.5). In contrast, when water was used as matrix, $L^{*}$ increased in both concentrations ( $L^{*}$ shifted from 85.7 to 86.5 in W-2CNC and from 84.5 to 85.9 in W-5CNC). CNC addition in AV (treatments $\mathrm{Av}-2 \mathrm{CNC}$ and $\mathrm{Av}-5 \mathrm{CNC}$ ) was

characterized by higher values of $a^{*}$ and $b^{*}$ (red orange tones) compared to the similar formulation in $\mathrm{W}(\mathrm{W}-2 \mathrm{CNC}$ and $\mathrm{W}-5 \mathrm{CNC}$, respectively).

Lignin affected colour change after dipcoating much more compared to the $\mathrm{CNC}$

Tab. 3 - Mean values ( \pm standard deviation) of weight before and after dip-coating in coatings and coating thickness after fully drying.

\begin{tabular}{lcccc}
\hline Treatment & $\begin{array}{c}\text { Before dip- } \\
\text { coating }(\mathbf{g})\end{array}$ & $\begin{array}{c}\text { After dip- } \\
\text { coating }(\mathbf{g})\end{array}$ & $\begin{array}{c}\text { Weight gain } \\
(\%)\end{array}$ & $\begin{array}{c}\text { Thickness } \\
(\boldsymbol{\mu m})\end{array}$ \\
\hline Av & $0.244 \pm 0.028$ & $0.316 \pm 0.026$ & 23 & $7.11 \pm 0.05$ \\
\hline Av-2CNC & $0.249 \pm 0.027$ & $0.279 \pm 0.028$ & 11 & $6.70 \pm 0.03$ \\
\hline Av-2LN & $0.256 \pm 0.014$ & $0.285 \pm 0.014$ & 10 & $4.98 \pm 0.05$ \\
\hline Av-5CNC & $0.254 \pm 0.016$ & $0.291 \pm 0.019$ & 13 & $5.14 \pm 0.04$ \\
\hline Av-5LN & $0.263 \pm 0.011$ & $0.289 \pm 0.013$ & 9 & $6.96 \pm 0.02$ \\
\hline W-2CNC & $0.238 \pm 0.026$ & $0.275 \pm 0.028$ & 14 & $3.84 \pm 0.01$ \\
\hline W-2LN & $0.239 \pm 0.025$ & $0.252 \pm 0.027$ & 14 & - \\
\hline W-5CNC & $0.238 \pm 0.028$ & $0.252 \pm 0.028$ & 6 & $2.72 \pm 0.02$ \\
\hline W-5LN & $0.246 \pm 0.021$ & $0.251 \pm 0.021$ & 2 & - \\
\hline
\end{tabular}

Tab. 4 - Contact angle of coated wood after water drop was released and wetting time needed for complete absorption. Solid content is also reported.

\begin{tabular}{lccc}
\hline Treatment & Contact angle (deg) & Wetting time & Solid content (\%) \\
\hline Control & 0 & $5^{\prime} 30^{\prime \prime}$ & - \\
\hline CNC & - & - & 92.6 \\
\hline LN & - & - & 95.6 \\
\hline Av & 44.3 & $45^{\prime}$ & 34 \\
\hline Av-2CNC & 56.33 & $25^{\prime}$ & 35.17 \\
\hline Av-2LN & 39.55 & $30^{\prime}$ & 35.23 \\
\hline Av-5CNC & 54.16 & $45^{\prime}$ & 36.93 \\
\hline Av-5LN & 49.9 & $45^{\prime}$ & 37.08 \\
\hline W-2CNC & 28.5 & $2^{\prime} 30^{\prime \prime}$ & 1.85 \\
\hline W-2LN & $1^{\prime} 30^{\prime \prime}$ & 1.91 \\
\hline W-5CNC & 53.5 & $9^{\prime}$ & 4.63 \\
\hline W-5LN & 37.15 & $3^{\prime}$ & 4.78 \\
\hline
\end{tabular}

samples, as indicated by the highest $\Delta E^{*}$ values, with an increase of $\Delta E^{*}$ when lignin concentration rises from $2 \%$ to $5 \%$. The most evident changes were decreasing brightness and a strong drift towards blue (increasing $b^{*}$ ).

While colour changes were strong when using lignin and CNC as additives for acrylic varnish, the differences in colour before and after dip-coating are less evident when water is used as medium for the respective coating formulations.

It is important to remark that when adding lignin to the used acrylic coating, a colour change towards green was observed, which might be due to lignin structural modification during polymerization of the acrylic resin.

A PCA analysis was performed on 324 replicates for colour measurements (Fig. 2c). The PCA showed three different clusters, whose grouping depended mainly on the concentration but also on the type of additive (LN or CNC). In fact, formulations with lignin were mostly grouped together (AV-2LN, AV-5LN, W5LN). However, W-2LN clustered together with the other formulations with $2 \%$ concentration. The last group is formed by the highest percentage of CNC for both commercial acrylic coating and water formulations (AV-5CNC and W$5 \mathrm{CNC}$ ). This means that colour change is influenced by both additive type and concentration.

\section{Weight and thickness}

In Tab. 3 the weight of the samples before and after dip-coating is reported, as well as the final coating thickness measured using an optical microscope.

Samples dipped in Av showed an increase in weight of about $23 \%$, whereas a lower weight gain was observed when CNC or lignin were added to the acrylic coating (Tab. 3). Further, no significant difference in weight gain between the two concentra- 
Fig. 3 - Bacterial activity of the various coating formulations after $20 \mathrm{~h}$ of incubation at $37^{\circ} \mathrm{C}$. (a) Samples $\mathrm{Av}, \mathrm{Av}-2 \mathrm{CNC}$ and Av2-LN; (b) samples Av-5CNC, Av$5 \mathrm{LN}$ and $\mathrm{W}-2 \mathrm{CNC}$; (c) samples $\mathrm{W}-2 \mathrm{LN}, \mathrm{W}-5 \mathrm{CNC}$ and W-5LN.

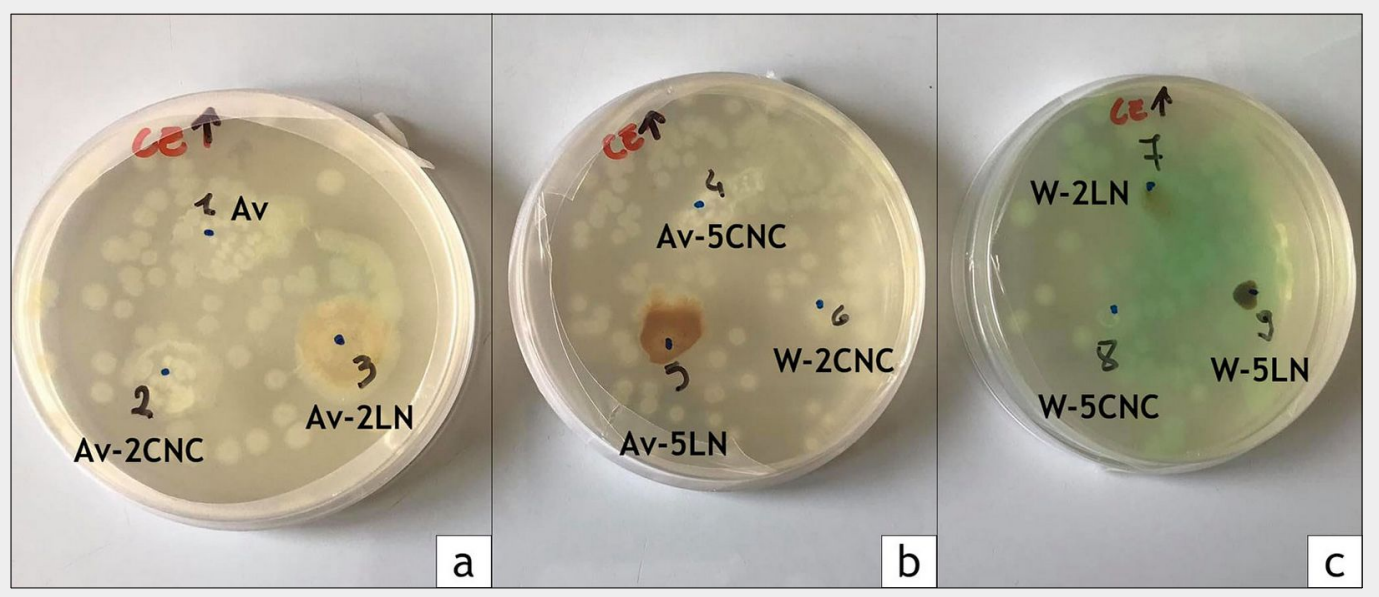

tions of CNC and LN used was recorded. Surprisingly, CNC addition decreased the thickness of the final coating with increasing CNC concentration. This might be due to a chemical reaction between $\mathrm{CNC}$ and the acrylic resin; after water evaporation, there might be a curing between CNC particles due to hydrogen bonds. Higher hy drophobicity of lignin, limiting the homogenization with acrylic varnish and water, could explain the higher final thickness compared to the CNC-modified coatings.

A PCA analysis was performed also on weight variation (Fig. 2d). In this case, only Av, W-5CNC and W-2LN formed a cluster. This means that $A v$ affected the weight variation as well as $\mathrm{W}-2 \mathrm{LN}$ and $\mathrm{W}-5 \mathrm{CNC}$. In fact, since lignin has a high molecular weight, CNC-modified coating can be comparable to lignin only if $\mathrm{CNC}$ concentration is $5 \%$.

The thickness of the coating was negligible, especially when using water as medium.

\section{Surface wettability test}

Tab. 4 shows internal contact angle, wet ting time and solid content of the different coating formulations tested.

Wetting tests showed that $A v-5 \mathrm{LN}$ increased the contact angle making the surface more hydrophobic. Such effect is even stronger when only water was used as medium instead of $A v(W-2 L N, W-5 L N)$. However, their respective wetting times are strongly reduced compared to the acrylic coatings.

Surprisingly, CNC at $2 \%$ led to an increase of the contact angle showing a more water-repellent behaviour. By adding 5\% of $\mathrm{CNC}$, a similar increase in contact angle was observed, but additionally wetting time was comparable to the acrylic coating (Av). Likely, CNC forms intensive hydrogen bonds with the waterborne acrylic coating, making the $\mathrm{OH}$ groups in wood less accessible for water. Indeed, increase of contact angle corresponds also to a small increase in solid content.

\section{Antibacterial activity test}

As mentioned above, two parallel tests were conducted in order to monitor the antibacterial activities of the samples, one using only the coating formulations and the other using the coated wood samples. In Fig. 3 the first part of the test is shown, where the varnish solutions were placed on agar plates, previously inoculated with bacterial suspension, and the image was taken after $20 \mathrm{~h}$ of incubation at $37^{\circ} \mathrm{C}$. In the samples W-2LN, W-5LN and W-5CNC a blue-green colouring appeared after $12 \mathrm{~h}$, which can be attributed to the production of phenazines (i.e., pyocyanin and other "accessory respiratory pigments" - Dietrich et al. 2013).

As shown in Fig. 3, bacterial growth was observed soon after the coating samples were placed on agar plates. Bacterial colonies were well developed in every formulation, but a significant difference was noticed between the samples in the first two plates (Fig. 3a, Fig. 3b) and the samples in the last plate (Fig. $3 \mathrm{C}$ ). A more intense bacteria activity is indicated by the green-blue colour of the agar plate in Fig. $3 c$, corresponding to the water-based formulations mixed with lignin and cellulose nanocrystals. However, also in the first two plates, containing the formulations $\mathrm{Av}, \mathrm{Av}-2 \mathrm{CNC}$, Av- $2 \mathrm{LN}, A v-5 C N C, A v-5 \mathrm{LN}$ and $\mathrm{W}-2 \mathrm{CNC}$, bacterial colonies were numerous and large. Thus, it could be concluded that none of the coatings proved an antibacterial effect. The blue-green colour in Fig. $3 c$ derives from the bacterial redox state, because $P$. aeruginosa produces pigments as secondary metabolites (i.e., pyocyanin, fluorescein, pyorubrin and pyomelanin) when reaching a stationary growth phase, often related to quorum sensing (QS) responses and modulation of pyocyanin as virulence factor (Sana et al. 2019). This response was more visible around the sample spots where the formulation contains lignin (sample 3 in Fig. 3a).

In the second part of the experiment, the coated wood specimens of the selected formulations were analyzed in comparison with virgin wood as control sample. The results showed that all of the treated samples were subjected to bacterial attack, although it seems that in the sample coated with pure $A v$ an alteration in colony morphology occurred. The colony sizes near the control and distanced from Av were smaller (about $1 \mathrm{~mm}$ in diameter) in comparison to the size observed around the $A v$ sample spots (diameter $>3 \mathrm{~mm}$ ). Additionally, in the lignin-coated samples, even larger colonies with diameter $>4 \mathrm{~mm}$ were observed (Fig. 4).

\section{FTIR spectroscopy and FTIR mapping analysis}

In Fig. 5 the FTIR spectra of untreated wood (Virgin wood), pure acrylic resin (Av pure) as well as coated samples ( $A v$ on wood, Av-5CNC and Av-5LN) are shown. IR band assignments for beech wood were listed according to Bodîrlau et al. (2008) while acrylic IR band assignments were found in Rao et al. (2019) and Akbarnezhad et al. (2020). After wood coating, the IR bands which are exclusively attributed to

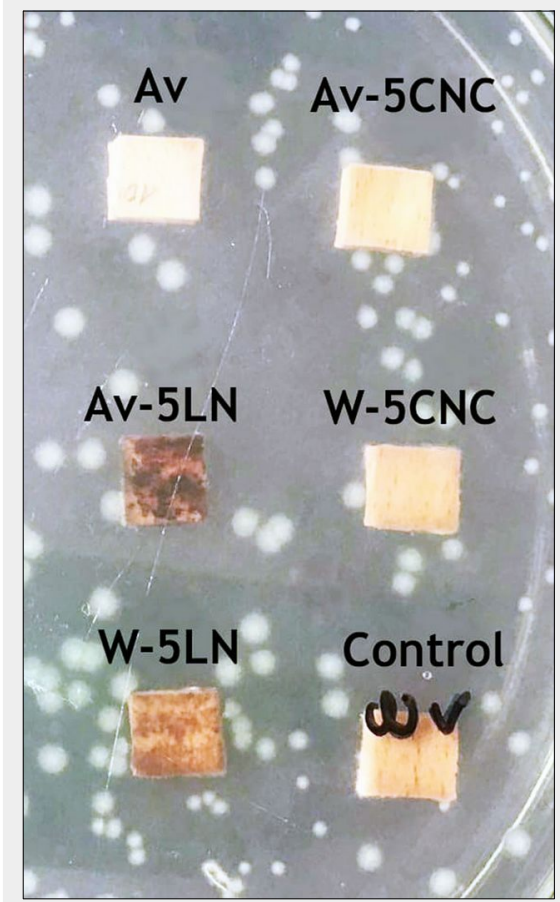

Fig. 4 - Antibacterial activity test of treated beech wood samples after $24 \mathrm{~h}$. 


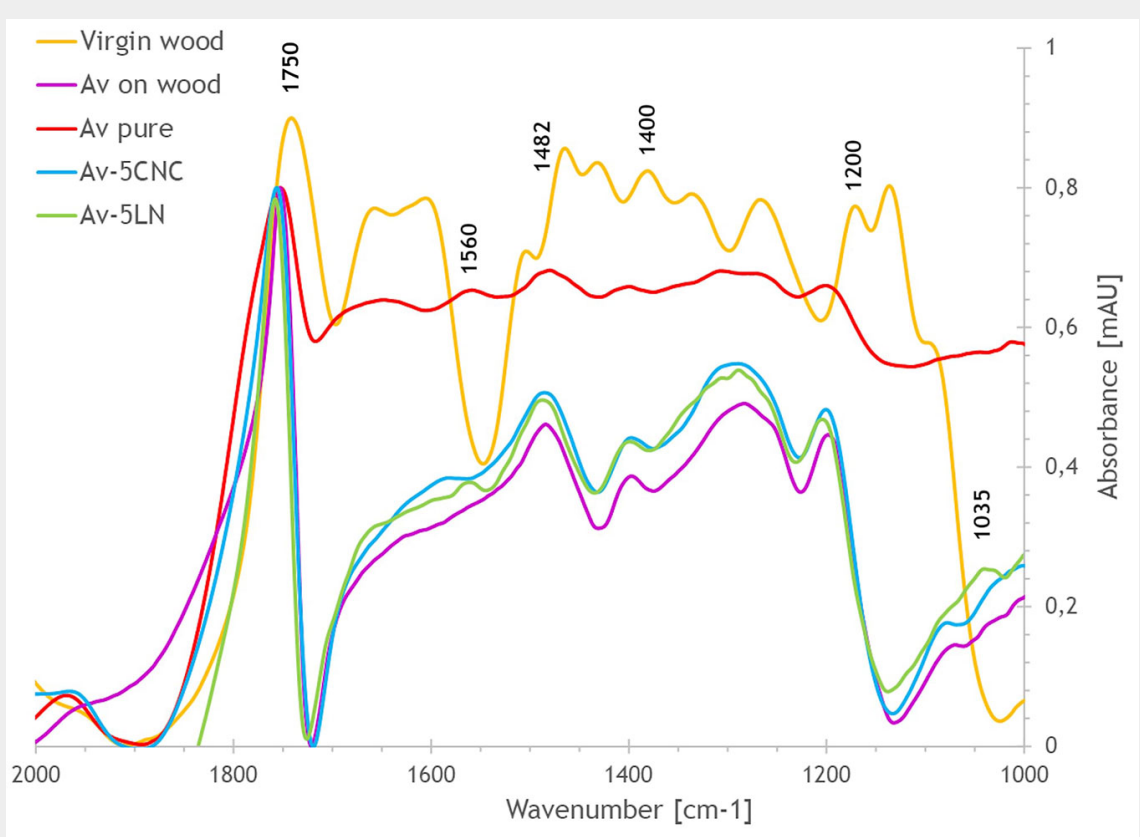

Fig. 5 - Comparison of FT-IR spectra of pure acrylic resin (Av), control sample (Virgin wood), and Av-coated wood (Av on wood); FT-IR spectra of CNC and LN mixed with $A v(A v-5 C N C, A v-5 L N)$ and pure acrylic resin (Av pure) are displayed.

wood, disperse under the Av signal, the spectrum becomes flat and the most prominent peaks $\left(1750,1482,1400,1200 \mathrm{~cm}^{-1}\right)$ are related to acrylic varnish. Conversely, the peak at $1284 \mathrm{~cm}^{-1}$ in the spectrum of $A v$ on wood seems to be the sum of several peaks related to both wood and acrylic coating. In Fig. 5 the spectra of the coatings Av-5CNC and Av-5LN did not show relevant differences since the predominant signal is still from the acrylic matrix of the coating. In particular, in Av-5LN peaks at 1560 and $1035 \mathrm{~cm}^{-1}$, also present in Av pure, are still evident. The peak at $1560 \mathrm{~cm}^{-1}$ in Av-5LN can be assigned to C-N (Yan et al. 2020) and the one at $1035 \mathrm{~cm}^{-1}$ can be attributed to the aromatic $\mathrm{C}-\mathrm{H}$ in-plane deformations as well as $\mathrm{C}=\mathrm{O}$ stretching of lignin (Zikeli et al. 2020). However, significantly more signal noise was registered for the lignin containing coating Av-5LN, which suggests heterogeneity of the prepared coating layer.
FTIR mapping was applied in order to investigate the homogeneity and distribution of the coatings and their CNC and lignin additives on the surface of the wood samples. In Fig. 6 the IR band at $1750 \mathrm{~cm}^{-1}$, assigned to carbonyl groups in methacrylate and holocellulose in beech wood (Bodîrlau et al. 2008), was used as the base for the image. In Fig. 6b, related to the sample containing cellulose nanofibrils, there are clearly areas with lower absorbance, attributed to CNC presence where the carbonyl band is less abundant relative to $A v$.

\section{Discussion}

Acrylic varnishes have interesting properties, as they are available in water-borne formulations and are therefore considered less toxic than solvent-borne products. In general, acrylic coatings show a quite interesting colour stability, but they are sensitive to mold fungi on the wood surface during weathering (Akbarnezhad et al.
2020) and for this reason increasing their resistance to biotic attack is a goal to be pursued. Water repellent coatings can contribute to its resistance, but in this case a sufficient water vapour permeability is necessary to allow moisture escaping from the wood surface after a wetting event (Gibbons et al. 2020).

The addition of nanocellulosic materials represents a viable approach to enhance the functionality and the end user value of coatings. Because of their morphology, nanocellulosic materials provide a large surface-to-volume ratio, which allows to interact intensively with the surrounding wood components, therefore enhancing the mechanical properties of wood (Kluge et al. 2017).

While inorganic nanoparticles have already been implemented in various coating solutions, the addition of bio-based nanofillers is still at an early development stage and mostly studied at the laboratory level.

In this study, CNC showed a satisfying performance regarding water sorption, as indicated by the higher contact angle recorded. The best results were obtained with the highest percentage of $\mathrm{CNC}$, which is consistent with Kluge et al. (2017), who showed that water repellence of acrylic based formulations was not negatively affected by nanocellulose addition. Av resin polymerization in presence of CNC might have shielded the $\mathrm{OH}$ functional groups of CNC from water, while CNC could have served as a structural scaffold during polymerization, leading to a higher water repellence than observed for pure Av resin.

Further encouraging results from $\mathrm{CNC}$ addition to $A v$ were that weight gain and solid content after dip-coating did not significantly increase compared to the original $A v$ varnish, but CNC at $2 \%$ conferred a certain degree of hygroscopicity. Increasing CNC percentage, it was observed an increased wetting time, even if the solid content was at almost the same measured at $2 \%$ in CNC concentration. This result introduces a different perspective on the role of solid content, which in coating technology has proved to directly correlate with hydrophobicity (Kluge et al. 2017), but in the specific application of CNC the network of (a)

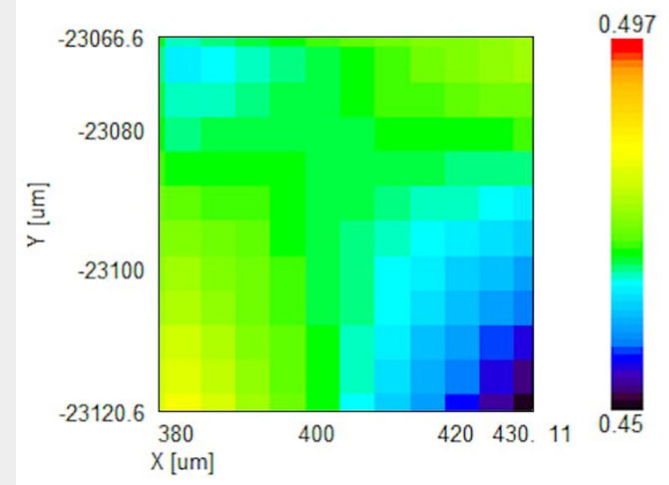

(b)

Av-5CNC

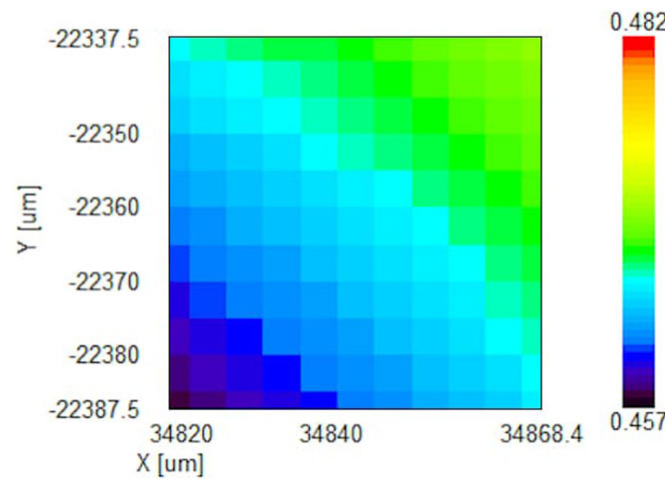

Fig. 6 - FT-IR mapping of acrylic coating mixed with

(a) $5 \%$ lignin $(A v-5 L N)$ and (b) CNC (Av-5CNC), for the peak at $1750 \mathrm{~cm}^{-1}$. 
nanocrystal add new properties less affected by the parameter of solid content.

The addition of CNC to wood coatings showed a weak impact on optical properties. In fact, $\Delta E^{*}$ was low and $a^{*}$ was quite similar to the previous status, but $b^{*}$ decreases slightly. This might depend on the small size of the CNC particles, as previously reported by Kluge et al. (2017). In other words, the nanocrystal dimensions allow the light to pass through the coating film without redirecting the beam. Therefore, if the aesthetical features of the product shall be preserved, coating with $\mathrm{CNC}$ additives is a valid approach.

Concerning bacterial interaction with CNC, cellulose nanofiber (with diameter range 2.3-4.5 nm and length 44-108 nm) were not able to hinder bacterial growth. This finding is in agreement with De Cesare et al. (2019), who reported an adaptive growth interaction of bacterial cells with eco-compatible nanofibers with a higher diameter range of 10-100 nm. Nevertheless, it is well described that Burkholderia and Pseudomonas strains, but also E. coli isolates, are able to attack nanomaterials and produce biofilms on them via sessile growth (Rieger et al. 2013, Rumbo et al. 2018, De Cesare et al. 2019).

Using CNC as an additive, a light (or at least a coating not heavier compared to pure $A v$ ) and thin coating but with interesting properties like transparency and uncompromised hydrophobicity can be obtained. However, since we registered no clear improvement of properties compared to the pure Av coating, no evident advantage for industry was found so far. To this aim, further analyses are needed aimed to investigate the effects of decreasing the solid content of the acrylic varnish on wood mechanical properties, which has proven quite promising (Kluge et al. 2017, Poaty et al. 2014, Veigel et al. 2014).

In this study, the viscosity of coatings was not analysed, though this parameter should be taken in consideration for industrial applications, as it could compromise coating sprayability and additives dispersion. We analyzed CNC dispersion by FT-IR mapping and some areas with low absorbance were visible, likely due to CNC aggregation (Fig. 6). Similarly, Marini et al. (2020) noticed that chemical modification of CNC needs to be considered to ensure the homogenous dispersion of CNC, even if it might affect costs and feasibility of the coating production at an industrial level.

Lignin has huge potential for future coating formulations because of its hydrophobic nature. In this study, lignin mixed with water gave better results than mixed with $A v$ regarding the contact angle, but the wetting time using $2 \%$ of lignin (W-2LN) was too low compared to Av coating (Tab. 4 ). This could be explained by a not homogenous dispersion of lignin in the coating (see Fig. 1). Thus, the chemical modification of lignin seems more important than for cellulose in order to increase its misci- bility. Several investigations focused on the addition of lignin to polyurethane-based coatings (Griffini et al. 2015, Klein et al. 2019), but studies on lignin in acrylic coatings are rare.

Concerning colour change, a content-depending shift to bluer and darker colour was recorded in all lignin-containing formulations. Therefore, lignin application on coated wood affects its original colour, but this permits additional wood protection against UV light as lignin acts as UV absorber (Teaca et al. 2019). Hence, according to Ozgenç et al. (2020), lignin can provide colour stabilization when a waterborne acrylic coating is applied in outdoor condition, because transparent coatings require more frequent maintenance than pigmented coatings, as UV light penetrates and degrades the film layer and decomposes the wood underneath (Oberhofnerová et al. 2019).

Our results show that lignin did not add antibacterial activity to wood coating as expected. This finding seems to be in contrast with Teaca et al. (2019), who reported that phenols leached from lignin can be absorbed by treated wood surfaces and act efficiently as biocides, when testing against rot fungi. However, $P$. aeruginosa strain AP02-1 is an environmental isolate with hydrocarbon-degrading abilities and able to tolerate and co-metabolize some aromatic compounds (Perfumo et al. 2006, Qi et al. 2015). This could explain the limited efficacy of lignin in inhibiting PA02-1 growth. Surprisingly, the PA02-1 isolate can exploit lignin for accelerating the external production of QS factors (pyocyanin), often involved in the virulence and adaptive response to environment of $P$. aeruginosa (Sana et al. 2019). However, this effect might appear higher in W-LN formulations and less evident in the Av-LN ones, and this might suggest, at least for this strain, that $A v$ is able to produce delaying effects in QS responses, specifically related in the production of phenazines. Interestingly, Av and lignin interact in the alteration of colony morphology. For $P$. aeruginosa, the different aspect of colonies may reflect difference in cell virulence. In this work morphological evolution of the CFU near the wood coated with $A v$ and with Av-LN mixture show a larger colonies which can be associated with enhanced adaptive response to the stressing environment (Sousa et al. 2013). However, in this case the Av coating is less related to size enlargement of the colonies in respect to Av-LN mixture, and this might indicate that wood interacts with some components of acrylic varnishes reducing eco-toxicity. On the other hand, the W-LN mixtures are not associated to relevant variation of morphotype, and thus we hypothesize that lignin was strongly adsorbed to the wood structure and not diffused around the material. The fast production of phenazines in $P$. aeruginosa induced by the W-LN formulations is intriguing, because pyocyanin has proved to be efficient against fungi and bacteria and it can be considered a relevant biotechnological metabolite with antimicrobial activity (Hamad et al. 2020) which could be also used as a purified component of $A v$.

FTIR mapping has proved to be an efficient tool to test the homogeneity of wood coatings with bio-based additives. Indeed, we observed a low absorbance in some areas where CNC and lignin apparently aggregated during coating. This could represent a fairly relevant problem which still hampers the industrial application of such bio-based additives.

\section{Conclusions}

In this study, the use of CNC as an additive to wood coatings showed promising results. A high percentage (5\%) of CNC in acrylic coatings decreased water sorption of beech wood, with no weight gain and a low colour change. The main disadvantage was the lack of any bacterial resistance. Flocculation of CNC particles is also a wellknown weakness which must be overcome before their industrial application.

Mixing lignin with Av did not add any significant improvement to coatings. Lignin showed a better water sorption with water as a formulation matrix (both in W-2LN and in $\mathrm{W}-5 \mathrm{LN}$ ). Also, a colour change of wood samples was observed using lignin mixed with $A v$ as coating, which indicates an unknown chemical reaction. For both cellulose and lignin, particle agglomeration was evident using FTIR mapping. The results obtained from bacterial resistance tests open new perspectives because the addition of lignin apparently promotes the production of secondary metabolites in the medium (i.e., pyocyanin, fluorescein, pyorubrin and pyomelanin) which could act as biocontrol agents against other pathogens.

From the point of view of coating industry, it seems more viaable to produce acrylic coatings mixed with $\mathrm{CNC}$, also because CNC production is almost at pre-industrial scale and the investigated properties are quite interesting. Yet, further research is needed and several unresolved tasks need to be completed before the industrial application of coatings with lignin and acrylic formulations, while mixing lignin with polyurethane seems more feasible. Furthermore, lignin has a high variability and the final properties depend on the extraction process, so its use at industrial scale still needs to be improved.

CNC and lignin are renewable and highly abundant resources, but the currently limited usage of these two compounds urgently calls for their more efficient application, in order to add value to industry sidestreams and create new bio-based materials for bio-building applications.

\section{Author Contribution}

Experimental plan MR. Data acquisition JJ and ST, Results and Discussion all the authors. First draft MR, EDM, ST and JJ. Re- 
viewing, checking and improving the manuscript GSM, FZ and VV. Final version checked by all the authors.

\section{Acknowledgements}

This study started in the frame of PRINMIUR 2015 (Research Projects of National Interest by the Italian Ministry of Education, University and Research) "Wood value-chain" project, grant no. 2015YW8 JWA, coordinated by G. Scarascia Mugnozza. Further support was received by the "Departments of Excellence - 2018" program (Dipartimenti di Eccellenza) of the Italian Ministry of Education, University and Research for the project "Landscape 4.0 Food, wellbeing and environment" of the Department for Innovation in Biological, Agro-Food and Forest Systems (DIBAF) of the University of Tuscia. This study has continued in the frame of the pfoject PONMISE ("Imprese e Competitività") F/2000 03/01-03/X45 "Innovazione e sostenibilità della filiera Foresta-Legno: bioeconomia circolare del legno e valorizzazione di foreste dell'Italia centro-meridionale".

\section{References}

Ago M, Tardy BL, Wang L, Guo J, Khakalo A, Rojas OJ (2017). Supramolecular assemblies of lignin into nano- and microparticles. MRS Bulletin 42 (5): 371-378. - doi: 10.1557/mrs.2017.88 Akbarnezhad M, Rasouli D, Yousefi H, Mashkour $M$ (2020). Weathering performance of beech wood coated with acrylic paint containing UV stabilizers of dihydroxy benzophenone and nano zinc oxide. Drvna Industrija 71 (4): 403409. - doi: 10.5552/drvind.2020.1912

Bodîrlau R, Teaca CA, Spiridon I (2008). Chemical modification of beech wood: effect on thermal stability. BioResources 3 789-800. - doi: 10.1537 6/biores.3.3.789-800

Brunetti M, Nocetti M, Pizzo B, Aminti G, Cremonini C, Negro F, Zanuttini R, Romagnoli $M$, Mugnozza G (2020). Structural products made of beech wood: quality assessment of the raw material. European Journal of Wood and Wood Products 78: 961-970. - doi: 10.1007/s00107-02001542-9

Chirkova J, Andersone I, Andersons B, Kurnosova N (2009). Lignin as a modifier for enhancing the durability of wood. Pro Ligno 5 (2): 7177. [online] URL: http://www.proligno.ro/en/art icles/2009/2/paper7.htm

De Angelis M, Romagnoli M, Vek V, Poljanšek I, Oven $P$, Thaler N, Lesar B, Krzišnik D, Humar M (2018). Chemical composition and resistance of Italian stone pine (Pinus pinea L.) wood against fungal decay and wetting. Industrial Crops and Products 117 187-196. - doi: 10.1016/j.indcrop. 2018.03.016

De Cesare F, Di Mattia E, Zussman E, Macagnano A (2019). A study on the dependence of bacteria adhesion on the polymer nanofibre diameter. Environmental Science: Nano 6 (3): 778797. - doi: 10.1039/C8EN01237G

Delfanti LMP, Bedini R, Romagnoli M, Recanatesi F, Meacci F, Caruso L, Manzo A, Salvati L (2014). Estimation of agroforestry biomasses available for energy purposes in a municipality in central Italy as instrument for energy planning. Applied
Mathematical Sciences 8 (131): 6577-6587. - doi: 10.12988/ams.2014.46442

Dietrich LE, Okegbe C, Price-Whelan A, Sakhtah H, Hunter RC, Newman DK (2013). Bacterial community morphogenesis is intimately linked to the intracellular redox state. Journal of Bacteriology 195 (7): 1371-1380. - doi: 10.1128/jb.022 73-12

Dos Santos P, García A, Cademartori PH, Gatto DA, Labidi J (2012). Study of the use of organosolv lignin as bio-preservative of wood. In: Proceedings of the "2012 IUFRO Conference IRG Annual Meeting" (Products DF). Lisbon (Portugal) 8-13 July 2012. IRG Secretariat, Stockholm, Sweden, pp. 1-11.

Gao L, Gan W, Xiao S, Zhan X, Li J (2016). A robust superhydrophobic antibacterial $\mathrm{Ag}-\mathrm{TiO}_{2}$ composite film immobilized on wood substrate for photodegradation of phenol under visiblelight illumination. Ceramics International 42 (2): 2170-2179. - doi: 10.1016/j.ceramint.2015.10.002 Gibbons MJ, Nikafshar S, Saravi T, Ohno K, Chandra S, Nejad M (2020). Analysis of a wide range of commercial exterior wood coatings. Coatings 10 (1013): 1-19. - doi: 10.3390/coatings10111 013

Goswami J, Haque E, Fox DM, Gilman JW, Holmes GA, Moon RJ, Kalaitzidou K (2019). The effect of cellulose nanocrystal coatings on the glass fiber-epoxy interphase. Materials 12 (12): 15. - doi: 10.3390/ma12121951

Griffini G, Passoni V, Suriano R, Levi M, Turri S (2015). Polyurethane coatings based on chemically unmodified fractionated lignin. ACS Sustainable Chemistry and Engineering 3 (6): 11451154. - doi: 10.1021/acssuschemeng.5boo073

Hamad MN-E, Marrez D, El-Sherbieny S (2020). Toxicity evaluation and antimicrobial activity of purified pyocyanin from Pseudomonas aeruginosa. Biointerface Research in Applied Chemistry 10 (6): 6974-6990. - doi: 10.33263/BRIAC10 6.69746990

Huang Z, Feng MW (2016). Studies of lignin as wood preservative - A literature review. In: Proceedings of the " $37^{\text {th }}$ Annual General Meeting". Vancouver (Canada). FP Innovation, Vancouver, Canada, pp. 4-6.

Klein SE, Rumpf J, Alzagameem A, Rehahn M, Schulze M (2019). Antioxidant activity of unmodified kraft and organosolv lignins to be used as sustainable components for polyurethane coatings. Journal of Coatings Technology and Research 16 (6): 1543-1552. - doi: 10.1007/ s11998-019-00201-w

Kluge M, Veigel S, Pinkl S, Henniges U, Zollfrank C, Roessler A, Gindl-Altmutter W (2017). Nanocellulosic fillers for waterborne wood coatings: reinforcement effect on free-standing coating films. Wood Science and Technology 51 601-613. doi: 10.1007/s00226-017-0892-y

Marini F, Zikeli F, Corona P, Vinciguerra V, Manetti M, Portoghesi L, Scarascia Mugnozza G, Romagnoli M (2020). Impact of bio-based (tannins) and nano-scale (CNC) additives on bonding properties of synthetic adhesives (PVAC and MUF) using chestnut wood from young coppice stands. Nanomaterials 10 (5): 956-968. doi: 10.3390/nano10050956

Oberhofnerová E, Simunková K, Dvorák O, Sterbová I, Hiziroglu S, Sedivka P, Panek M (2019). Comparison of exterior coatings applied to oak wood as a function of natural and artificial weathering exposure. Coatings 9: 864-878. doi: $10.3390 /$ coatings9120864

Ozgenç O, Durmaz S, Sahin S, Boyaci IH (2020). Evaluation of the weathering resistance of waterborne acrylic- and alkyd-based coatings containing HALS, UV absorber, and bark extracts on wood surfaces. Journal of Coatings Technology and Research 17 (2): 461-475. - doi: 10.1007/ s11998-019-00293-4

Paletto A, Bernardi S, Pieratti E, Teston F, Romagnoli M (2019). Assessment of environmental impact of biomass power plants to increase the social acceptance of renewable energy technologies. Heliyon 5 (7): e02070. - doi: 10.1016/j.heliyon.2019.e02070

Perfumo A, Banat IM, Canganella F, Marchant R (2006). Rhamnolipid production by a novel thermophilic hydrocarbon-degrading Pseudomonas aeruginosa AP02-1. Applied Microbiology and Biotechnology 72 (1): 132-138. - doi: 10.1007/ s00253-005-0234-0

Poaty B, Vardanyan V, Wilczak L, Chauve G, Riedl B (2014). Modification of cellulose nanocrystals as reinforcement derivatives for wood coatings. Progress in Organic Coatings 77 (4): 813820. - doi: 10.1016/j.porgcoat.2014.01.009

Qi J, Wang B, Li J, Ning H, Wang Y, Kong W, Shen $L$ (2015). Genetic determinants involved in the biodegradation of naphthalene and phenanthrene in Pseudomonas aeruginosa PAO1. Environmental Science and Pollution Research 22 (9): 6743-6755. - doi: 10.1007/s11356-014-3833-4 Rao F, Yahui Z, Bao M, Zhang Z, Bao Y, Li N, Chen Y, Yu W (2019). Photostabilizing efficiency of acrylic-based bamboo exterior coatings combining benzotriazole and zinc oxide nanoparticles. Coatings 9: 533-548. - doi: 10.3390/coating s9090533

Rieger KA, Birch NP, Schiffman JD (2013). Designing electrospun nanofiber mats to promote wound healing - A review. Journal of Materials Chemistry B 1 (36): 4531-4541. - doi: 10.1039/C3 TB20795A

Romagnoli M, Cavalli D, Pernarella R, Zanuttini R, Togni M (2015). Physical and mechanical characteristics of poor-quality wood after heat treatment. iForest - Biogeosciences and Forestry 8: 884-891. - doi: 10.3832/ifor1229-007

Romagnoli M, Fragiacomo M, Brunori A, Follesa M, Scarascia Mugnozza G (2019). Solid wood and wood based composites: the challenge of sustainability looking for a short and smart supply chain. In: "Digital Wood Design. Lecture Notes in Civil Engineering" (Bianconi F, Filippucci $M$ eds). Springer Internation Publishing, Cham, Switzerland, pp. 783-807. - doi: 10.1007/ 978-3-030-03676-8_31

Rumbo C, Tamayo-Ramos JA, Caso MF, Rinaldi A, Romero-Santacreu L, Quesada R, Cuesta-López $S$ (2018). Colonization of electrospun polycaprolactone fibers by relevant pathogenic bacterial strains. ACS Applied Materials and Interfaces 10 (14): 11467-11473. - doi: 10.1021/acsami. $7 \mathrm{~b} 19440$

Sana TG, Lomas R, Gimenez MR, Laubier A, Soscia C, Chauvet C, Conesa A, Voulhoux R, Ize B, Bleves $S$ (2019). Differential modulation of quorum sensing signaling through QsIA in Pseudomonas aeruginosa strains PAO1 and PA14. Journal of Bacteriology 201 (21): e00362-19. - 
doi: $10.1128 /$ jb.00362-19

Schulze P, Leschinsky M, Seidel-Morgenstern A, Lorenz H (2019). Continuous separation of lignin from organosolv pulping liquors: combined lignin particle formation and solvent recovery. Industrial and Engineering Chemistry Research 58 (9): 3797-3810. - doi: 10.1021/acs.iecr.8bo4 736

Sciomenta M, Spera L, Bedon C, Rinaldi V, Fragiacomo M, Romagnoli M (2021). Mechanical characterization of novel homogeneous beech and hybrid beech-corsican pine thin cross-laminated timber panels. Construction and Building Materials 271: 121589. - doi: 10.1016/j.conbuildmat.20 20.121589

Sousa AM, Machado I, Nicolau A, Pereira MO (2013). Improvements on colony morphology identification towards bacterial profiling. Journal of Microbiological Methods 95 (3): 327-335. - doi: 10.1016/j.mimet.2013.09.020

Teaca C, Rosu D, Mustata AC, Rusu T, Rosu L, Irina R, Varganici CD (2019). Natural bio-based products for wood coating and protection against degradation: a review. BioResources 14 (2): 4873-4901. - doi: 10.15376/biores.14.2.Teaca UNI-EN-335 (2013). Durability of wood and wood-based products - Use classes: definitions, application to solid wood and wood-based products. Italian Unification Body (UNI), Milan, Italy, pp. 20.

UNI-EN-350 (2016). Durability of wood and wood-based products - Testing and classifica- tion of the durability to biological agents of wood and wood-based materials. Italian Unification Body (UNI), Milan, Italy, pp. 32.

UNI-EN-ISO/CIE-11664-4 (2019). Colourimetry. Italian Unification Body (UNI), Milan, Italy, pp. 20.

Van Den Bulcke J, Rijckaert V, Van Acker J, Stevens $M$ (2006). Adhesion and weathering performance of waterborne coatings applied to different temperate and tropical wood species. Journal of Coatings Technology Research 3 (3): 185-191. [online] URL: http://go.gale.com/ps/an onymous?id=GALE|A150454368\&sid=googleSc holar\&v=2.1\&it=r\&linkaccess=abs\&issn $=154700$ 91\&p=AONE\&sw $=\mathrm{w}$

Vardanyan V, Galstian T, Riedl B (2014). Effect of addition of cellulose nanocrystals to wood coatings on color changes and surface roughness due to accelerated weathering. Journal of Coatings Technology and Research 12 247-258. doi: 10.1007/s11998-014-9634-3

Veigel S, Grüll G, Pinkl S, Obersriebnig M, Müller U, Gindl-Altmutter W (2014). Improving the mechanical resistance of waterborne wood coatings by adding cellulose nanofibres. Reactive and Functional Polymers 85 214-220. - doi: 10.1016/j.reactfunctpolym.2014.07.020

Yan X, Tao Y, Qian X (2020). Preparation and optimization of waterborne acrylic core microcapsules for waterborne wood coatings and comparison with epoxy resin core. Polymers (Basel) 12 (10): 2366 . - doi: $10.3390 /$ polym12102366
Zikeli F, Vinciguerra V, D'Annibale A, Capitani D, Romagnoli M, Scarascia Mugnozza G (2019). Preparation of lignin nanoparticles from wood waste for wood surface treatment. Nanomaterials 9 (2): 281-298. - doi: 10.3390/nanogo20281 Zikeli F, Vinciguerra V, Sennato S, Scarascia Mugnozza G, Romagnoli M (2020). Preparation of lignin nanoparticles with entrapped essential oil as a bio-based biocide delivery system. ACS Omega 5 (1): 358-368. - doi: 10.1021/acsomega. 9bo2793

Zikeli F, Vinciguerra V, Taddei Anna R, D'Annibale A, Romagnoli M, Scarascia Mugnozza G (2018). Isolation and characterization of lignin from beech wood and chestnut sawdust for the preparation of lignin nanoparticles (LNPs) from wood industry side-streams. Holzforschung 72 (11): 961-972. - doi: 10.1515/hf-2017-0208

Zmihorska-Gotfryd A (2004). Coating compositions based on modified phenol-formaldehyde resin and urethane prepolymers. Progress in Organic Coatings 49 (2): 109-114. - doi: 10.1016/j. porgcoat.2003.09.002

\section{Supplementary Material}

Fig. S1 - The experimental design of the present study.

Link: Jusic_3782@supploo1.pdf 